UDC 631.416 .9

(C) 2016

\author{
A. Fateyev, Doctor of Agricultural Sciences \\ NSC "IGA named after O.N. Sokolovsky " \\ V. Martynenko \\ Sumy branch of the Soil Institute of Soil Protection of Ukraine \\ M. Sobko, Candidate of Agricultural Sciences \\ Sumy Institute of Agriculture of the North East NAAN
}

\title{
PRODUCTIVITY OF CULTURES OF CROP ROTATIONS AND REMOVAL OF NUTRIENTS AT DIFFERENT FERTILIZER SYSTEMS AND SOIL CULTIVATION
}

The purpose. To study effect of moderate doses of artificial fertilizers, green manure crops and nonmerchantable produce of plant growing on productivity of 4field grain-beet crop rotation at different systems of soil cultivation and to determine removal of nutrients crops from soil. Methods. Field, laboratory, statistical. Results. Effect of organic and mineral fertilizer systems upon productivity of cultures of short crop rotation is studied at moldboard and minimum systems of cultivation as well as indexes of removal of nutrient elements of soil. It is determined that the highest productivity of crop rotation was at organic fertilizer system on the background of moldboard system of cultivation.

Conclusions. Moldboard system of soil cultivation in comparison with minimum one has ensured higher productivity of crop rotation in all alternatives of fertilizing. In particular, in alternative without fertilizing - for $37 \mathrm{c} /$ hectare of f.u., in organic and mineral systems accordingly — for 43 and 30 c/hectare of f.u. Moldboard cultivation of soils resulted in higher percentage of the content and removal of nutritive matters with the yield of cultures of crop rotation.

Key words: moldboard and minimum systems of soil cultivation, productivity of crop rotation, organic and mineral fertilizer systems.

Application of mineral and organic fertilizers is one of the main conditions and a powerful way of improving the productivity of crops. At the same time, when the application of traditional organic fertilizers was reduced so that it cannot meet the needs of agriculture in fertilizing fields, the use of alternative sources of organic matter becomes increasingly relevant. On the other hand, given the rapid rise in prices for mineral fertilizers, not all agribusinesses are able to use high 
cadmium doses for fertilizing crops due to financial difficulties and for other reasons.

All these factors indicate the need to introduce resource-saving technologies for growing agricultural crops, which minimize technological operations, energyconsuming traditional and soil tillage systems replaced with non-plow and other resource-saving cultivation systems [5], introduces elements of biologization of agriculture using as fertilizer non-market crop production together with the taking of the minimum doses of mineral fertilizers $[1,3]$.

According to many scientists, the use of siderates is an effective mean of improving the productivity of agricultural crops [2,4,6-7].

The purpose of research - to study the influence of moderate doses of mineral fertilizers, siderates and non-commercial crop production on different soil tillage systems on the productivity of crops of 4-plow crop rotation and determine the removal of nutrient elements from crops from the soil.

Methods of research. Field studies were conducted in the stationary experiment of the Agricultural Laboratory of the Sumy Institute of Agricultural Production (now the Institute of Agriculture of the North East of NAAS) during 2007-2010.

Soil was chernozem typical of large-dust-medium loamy with the following agrochemical parameters: humus content by Tyurin method $4.7 \%$, absorb capacity 28.06 mg-eq., hydrolytic acidity by Kappen 3.7 mg-eq /100g of soil, pH of salt 5.3, $\mathrm{pH}$ of water 6.8 , total nitrogen content by the Golubiev method $-0.23 \%$, gross phosphorus - $0.18 \%$, easily hydrated nitrogen by the Cornfield method - 112 , available compounds $\mathrm{P}_{2} \mathrm{O}_{5}$ and $\mathrm{K}_{2} \mathrm{O}$ by Chirikov, respectively, 190 and $106 \mathrm{mg}$ per $1 \mathrm{~kg}$ of soil.

The area of the crop area was $100 \mathrm{~m}^{2}$, the accounting $-50 \mathrm{~m}^{2}$, the repetitiveness of the experiment - 3 times, the method of placement of variants and repetitions - systematic.

In the experiment, we studied the 4- grain beet crop rotation, where the predecessor of winter wheat was siderane pair (sainfoin). After the winter wheat, 
sugar beet was sown, and then the barley was sown with the sowing of the sainfoin.

Control variant was that one where fertilizers were not used. The second variant was the organic fertilizer system, which involves the use of siderates for fertilizers (sideral sainfoin pairs under winter wheat) and non-market crop production (straw of winter wheat under sugar beets, a pile of beets under barley with sowing the sainfoin). The third variant was a mineral fertilizer system using the minimum doses of mineral fertilizers (sowing application and fertilization).

Various fertilizer systems of crop rotation were studied on 2 soil tillage systems: 1) plowing to a depth of $22-27 \mathrm{~cm}$; 2) surface tillage with disk implements - 6-8 cm.

Research results. Crops of field crop rotation had different productivity in converting the main products into feed units (Table).

Productivity of field crop rotation crops depending on fertilizer and soil tillage systems (2007-2010), c f. u./ha

\begin{tabular}{|c|c|c|c|c|c|}
\hline \multirow{2}{*}{$\begin{array}{c}\text { Variant of } \\
\text { experiment }\end{array}$} & \multicolumn{5}{|c|}{ Crop rotation } \\
\cline { 2 - 6 } & Barley & Sainfoin* & Wheat & Sugar beet & Total products \\
\cline { 2 - 6 } & \multicolumn{5}{|c|}{ Plow system of tillage } \\
\hline $\begin{array}{c}\text { Without } \\
\text { fertilizers }\end{array}$ & 34,1 & 56,6 & 63,1 & 88,5 & 185,7 \\
\hline Organic & 41,5 & - & 70,5 & 94,1 & 206,1 \\
\hline Mineral & 40,8 & 58,8 & 66,1 & 93,9 & 200,8 \\
\hline & \multicolumn{5}{|c|}{ Minimum soil tillage system } \\
\hline $\begin{array}{c}\text { Without } \\
\text { fertilizers }\end{array}$ & 33,9 & 48,0 & 49,5 & 65,2 & 149,6 \\
\hline Organic & 39,6 & - & 55,8 & 68,0 & 163,4 \\
\hline Mineral & 42,8 & 52,1 & 59,8 & 68,4 & 171,0 \\
\hline
\end{tabular}

*Productivity of the sainfoin in the total productivity was not taken into account

Organic and mineral fertilizer systems contributed to an increase in the productivity of spring barley by 16.8 - 26.3\% depending on the soil tillage systems. By the field system of soil cultivation productivity of barley was higher on the background of an organic fertilizer system (by $2 \%$ compared to mineral fertilizers), whereas by the minimum one it was mineral one ( $8 \%$ higher than organic ones). 
By minimal soil cultivation, there were better conditions for the absorption of nutrients from mineral fertilizers than from organic residues.

The productivity of winter wheat was higher at the background of plow soil tillage under the organic fertilizer system (by 12\% compared with control and by $7 \%$ - compared with mineral fertilizers). On the contrary, by the minimum system of tillage, mineral fertilizer system was more efficient - productivity increased by $21 \%$ compared to control and by $7 \%$ compared to organic, that is, the profits in the soil of the green mass of the esparticle reduces the efficiency of the siderate.

The productivity of the sainfoin was $13-18 \%$ higher than by the plow system of soil tillage.

Sugar beet by soil plow tillage system also had higher productivity than surface tillage for a 36-38\%. It should be noted that fertilization systems in efficiency were almost equal.

The dynamics of increasing productivity of crop rotation in general is due to the growth of the yield of major crops. The data obtained during 4 years, that is, for rotation of crop rotation, show the high efficiency of siderates and nonconsumable part of crop and mineral fertilizers due to improved conditions of plant growth and development, as well as high natural and effective fertility of chernozem typical medium loamy (Table).

In particular, in options without fertilizers, crop rotation productivity was 49.1 and $60.6 \mathrm{c} / \mathrm{ha}$ by the minimum and plow soil tillage system. That is, by the transition to a minimum system of soil tillage in the field crop rotation, its productivity decreased by almost $20 \%$.

The application of mineral fertilizers contributed to the increase of crop rotation productivity in accordance with 171 and $201 \mathrm{c} / \mathrm{ha}$, but here, against the background of the system of cultivating soil, the productivity was higher by 30 c/ha or by $17 \%$.

By plow soil tillage, the organic fertilizer system has some advantages over mineral fertilizers, but with the background of a minimal soil cultivation system, higher productivity of crop rotation is observed on the background of a 
fertilizer mineral system - at $8 \mathrm{c} / \mathrm{ha}$. The reason is the shallow placement of siderates, wheat straw and beet hives in the soil.

Therefore, the application of different fertilizer system and soil tillage systems has a significant effect on crop yield and crop rotation productivity, which varies widely.

For crop formation, crops use both the applicate nutrients and the nutrients that are available in the soil. Usually, in practice, the need in the nutrition elements by plants is determined taking into account their economic removal, withdrawn from the soil with harvested crop of commodity and non-food products.

As the calculations have shown, the economic removal of nutrition elements depends on several factors: harvest level, fertilizer system and soil cultivation (Figures 1 and 2). 


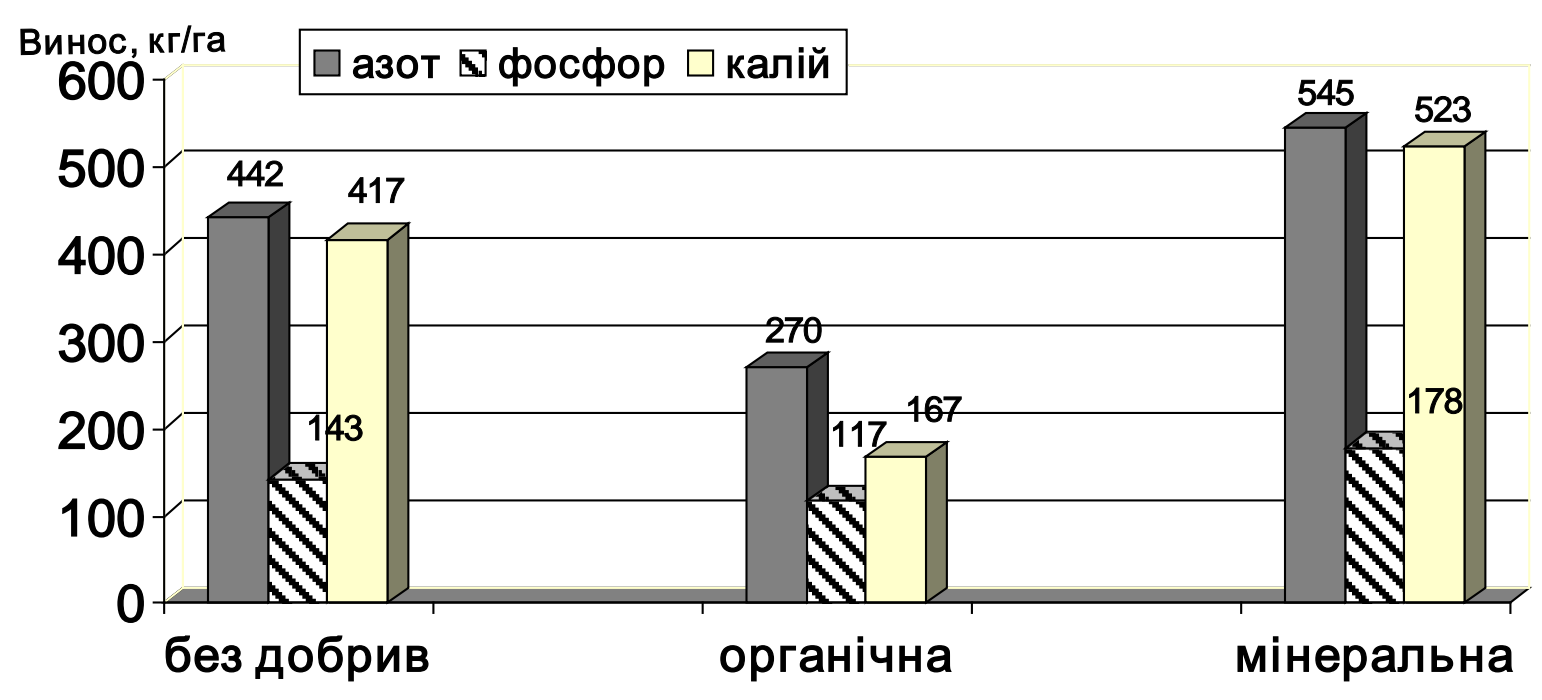

Система удобрення

Fig. 1 Economic removal of nutrient elements by crops of crop rotation during plow soil tillage depending on fertilizer systems, 2007-2010

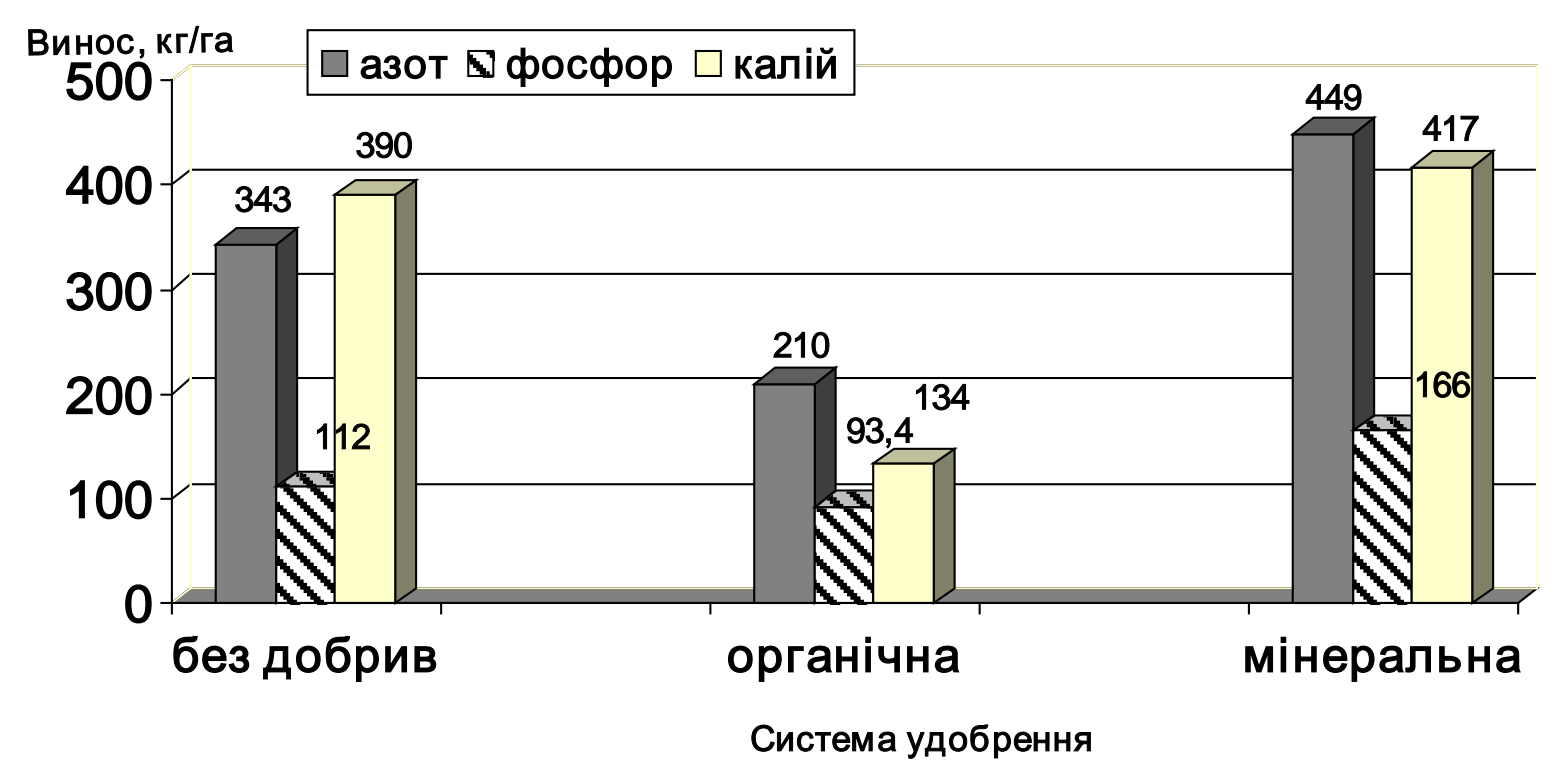

Fig. 2 Economic removal of nutrient elements by crops of crop rotation during minimal soil tillage depending on fertilizer systems, 2007-2010

In particular, as noted above, the total productivity of crop rotation against the background of plow soil tillage was higher than the minimum one, which was reflected in the economic removal of nutrients. In the unconventional version of the landing system, the removal of nitrogen, phosphorus and potassium was higher by $22 ; 21,9$ and $6,5 \%$, against the background of the organic fertilizer system - 
22,0; 20.5 and 19.8\%. On the mineral fertilizer system, the removal of nitrogen, phosphorus and potassium was higher here at 17,6; 18.0 and 20.2\%.

Significant dependence of the removal of nitrogen, phosphorus and potassium from the soil is also observed from different fertilizer systems of agricultural crops against the background of the plow and minimum soil tillage. Due to application of green mass of grainfoin, winter wheat straw and sugar beet slices, withdrawal of nitrogen decreased by $50.4 \%$ by organic fertilizer system, phosphorus by 34.3 and potassium by $68.1 \%$.

A similar pattern can be on a minimum system of tillage, respectively: 53.2; 43.7 and $67.9 \%$.

That is, the use in the organic system of the sainfoin as a siderate and straw of winter wheat and sugar beet for fertilizer, doubles the removal of nitrogen, 34$43 \%$ - phosphorus and $68 \%$ of potassium, without reducing the productivity of crop rotation on the plow system of soil tillage and for a small (by 4\%) decrease against the background of the minimal one.

\section{Conclusions.}

The higher productivity of the crop rotation is observed in the background of the plow soil tillage in all variants: without fertilizers - by 37 centners per hectare, in organic and mineral systems, respectively, at 43 and 30 centners per hectare.

On the background of the plow soil tillage system, the removal of nitrogen, phosphorus and potassium with crops of crop rotation was higher,.

The removal of individual elements from the soil decreased in number: nitrogen> potassium> phosphorus on the background of the organic fertilizer system and nitrogen $=$ potassium $>$ phosphorus.

Significant decrease in the removal of nutrients from the soil on the background of an organic fertilizer system due to the high productivity of crop rotation crops indicates a significant part of the non-consumable portion of the winter wheat and sugar beet harvest in combination with the seed crop in reducing the losses of nitrogen, phosphorus and potassium from the soil. 


\section{Bibliography}

1. Balayev A.D. Fertility of chernozem typical under long-term use of soil protection technologies of crops`cultivation / A. D. Balayev, I. V. Evnak, N. M. Manizhevska // Agrochemistry and Soil Science. - Kharkiv, 2006. - 2nd book- P. 8.

2. Berdnikov O.M. Role of Sederation in Modern Agriculture / O.M. Berdnikov, Yu.A. Nikitiuk // Bulletin of Agrarian Science - 2004 - No. 3. p.12- 15

3. Vaschenko V. Resource-saving technologies in plant growing / V. Vashchenko // Engineering of agrarian and industrial complex. - 1999. - №4. - P. 27-28.

4. Kulbida V.V. Leguminous crops and green fertilizers / V.V. Kulbida, O.O. Artyushenko, V.O. Borodin // Bulletin of Agrarian Science - 1995 - No. 11. - P.40-47.

5. Medvedev V.V. To a farmer about soil and resource-saving innovations in soil tillage / V.V. Medvedev - Kh.: Spec. In LLC "Smugasta typography", 2015. - P. 200

6. Melnychenko V. Siderates and New Approaches to them / V. Melnychenko, V. Artemenko // Agrosvit of Ukraine. - 1998. №2. - P. 11-13.

7. Sologub Yu. Green fertilizers and by-products in modern agriculture / Yu. Sologub, A. Andryushko // Agronomy. - 2004 - No. 4. - P. 70-72. 